\title{
Pandangan Abdullah Saeed Pada Konsep Nasikh Mansukh
}

\author{
Oleh: Aavi Lailaa Kholily \\ Email: mwardanibjm@gmail.com \\ UIN Sunan Kalijaga Yogyakarta
}

\begin{abstract}
Abstrak
Teori nasikh mansukh dari masa klasik hingga sekarang masih menjadi perdebatan antara ulama' terkait kesepakatan dan penolakan. Dan di antara ulama' yang sepakat adanya konsep nasikh mansukh dalam Alquran pun masing-masing memiliki kreteria sendiri-sendiri dalam menentukan konsep nasikh. Salah satu di antara ulama' yang sepakat adalah Abdullah Saeed, beliau seorang mufasir kontemporer yang menawarkan metode baru dalam menafsirkan Alquran yakni metode kontekstualis sehingga pada makalah ini peneliti tertarik mengkaji konsep nasikh mansukh menurut Saeed, alasan Saeed sepakat dengan adanya konsep nasikh mansukh dan relavansi nasikh mansukh menurut Saeed dalam menafsiri dan memahami teks-teks Alquran. Hasil dari kajian ini, peneliti menemukan beberapa hal, yakni: konsep nasikh menurut Saeed adalah pencabutan hukum dengan hukum yang datang setelanya, alasan Saeed setuju dengan adanya nasikh mansukh dalam Alquran adalah sebagai bentuk kemudahan yang Allah berikan kepada umat sesuai dengan kondisi dan situasi kebutuhan umat, kemudian untuk relevansi nasikh menurut Saeed dalam penafsiran adalah gagasan pencabutan hukum lewat nasikh dapat
\end{abstract}


menjadi pijakan untuk menafsiri ulang Alquran yang sudah tidak relevan agar bisa memenuhi kebutuhan umat yang sesuai dengan kondisi dan situasi.

Kata Kunci: Konsep, Nasikh Mansukh, Abdullah Saeed.

\section{PENDAHULUAN}

Ada beberapa devinisi menurut ulama' terkait nasikh dan mansukh, Subhi Shalih menjelaskan nasikh adalah penghilangan, pergantian dan pemindahan, sedangkan mansukh adalah hukum yang dibatalkan atau dihapus dengan batasan penghilangan hukum syar'i harus dengan hukum syar'i pula. Sedang as-Syatibi memberi penjelasan bahwa nasikh adalah pembatalan dengan beberapa batasan salah satunya pembatalan tersebut harus pada hukum yang lebih dulu ada dengan hukum baru. ${ }^{1}$

Menurut Abi Muhammad Maki bin Abi Thalib al-Quaisi dalam kitabnya al-Idhah al-Nasikhu Alquran kata nasikh berasal dari kalam arab yakni naskhtu al-kitab artinya saya memindahkan catatan dari kitab satu ke kitab yang lain namun tidak ada perubahan sama sekali dalam kitab yang dinaskh, naskhat al-syamsu al-dzillah bermakna menghilangkan dan mengantikan, naskhat al-rihu al-atsara yang artinya menghapus sesuatu dengan yang lain namun yang menghapus tidak harus menjadi pengganti dari yang dihapus. ${ }^{2}$ Definisi-definisi tersebut setidaknya mewakili bahwa secara umum ulama’ sepakat bahwa nasikh adalah sesuatu bentuk menghapusan namun mereka memiliki kreteria masing-masing yang menjadi perbedaan antara ulama' satu dengan yang lain dalam menentukan konsep nasikh mansukh.

1 Abu Bakar, “Kontraversi Nasikh Dan Mansukh Dalam Al-Qur’an," Madania: Jurnal IlmuIlmu Keislaman 6, No. 1 (1 Maret 2018): 50.

2 Wartoyo "Konsep Naskh Dalam Teori Hukum Mahmud Muhammad Thaha" Mahkama 1, No 2 (Desember, 2016): 147 
Dalam perjalanannya teori nasikh dan mansukh sering terjadi pro dan kontra di kalangan ulama', secara umum ada dua pendapat, pertama: mengingkari adanya nasikh dalam Alquran, pendapat ini dipelopori oleh Abu Muslim al-Ashfahani dengan dalil QS Fushshilat: 42 "Tidak datang kepadanya Alquran kebatilan baik dari depan maupun dari belakang” dengan ayat ini beliau menegaskan tidak ada pembatalan dalam Alquran, kedua: mengakui adanya nasikh dan mansukh dengan alasan nasikh dalam Alquran tidak bertujuan membuat bingung umat melainkan nasikh adalah salah satu bentuk kebijaksanan Allah. Perdebatan ini telah terjadi sejak masa klasik hingga kontemporer. ${ }^{3}$

Salah satu di antara ulama' yang mengakui adanya konsep nasikh mansukh adalah Abdullah Saeed, beliau seorang penafsir kontemporer yang menawarkan metode baru dalam menafsiri Alquran yakni metode kontekstualis. ${ }^{4}$ sehingga pada makalah ini, peneliti tertarik untuk membahas konsep nasikh mansukh menurut Abdullah Saeed, alasan beliau sepakat dengan adanya konsep nasikh mansukh ditengah perdebatan ulama' baik yang mengakui atau menolak konsep nasikh mansukh dan relavansi nasikh mansukh menurut Abdullah Saeed dalam menafsiri dan memahami teks-teks Alquran sebagai kitab petunjuk agar selalu relavan untuk kontek sekarang dan masa yang akan datang.

Sebelumnya telah ada beberapa penelitian yang membahas nasikh mansukh diantaranya tulisan Hasan Asy'ari Ulama’i' dalam tulisannya berjudul Konsep Nasikh dan Mansukh Dalam Alquran, ditulisannya ini beliau menjelaskan pembahasan terkait nasikh dan mansukh adalah pembahasan yang sangat penting dalam menafsiri Alquran untuk

3 Reflita Reflita, “Redefinisi Makna Nasakh Internal Ayat Al-Qur’an," Substantia 19, No. 1 (3 Februari 2018): 31.

4 Lien Iffah Naf'atu Fina Penafsiran Kontekstualis Atas Al-Qur'an, Terjemahan Dari Buku Interpretasi The Quran: Towards A Contemprary Approach (Yogyakarta: Lembaga Ladang Kata, 2016), Hal. 2. 
menghindari kesalahan dalam penafsiran, menurutnya walaupun masalah nasikh dan mansukh masih terjadi pro dan kontra namun hal tersebut bukanlah keputusan akhir yang masih memungkinkan untuk berubah, ia juga menegaskan bahwa meskipun banyak dari kalangan intelektual tidak sepakat adanya nasikh dan mansukh tetapi pendapat yang lebih disepakati banyak ulama' adalah pendapat yang mengakui adanya nasikh dan mansukh. ${ }^{5}$

Masih terkait nasikh dan mansukh, pembahasan ini juga dilakukan oleh Labibul Wildan dalam tesisnya yang berjudul Konsep Nasikh dan Mansukh Dalam Perspektif Akhmad Mustafa al-Maragi dan Mahmoud Taha, tesis ini berisi pandangan Akhmad Mustafa al-Maragi dengan Mahmoud Taha tentang nasikh dan mansukh begitu juga dengan persamaan dan perbedaan di antara keduanya. ${ }^{6}$

Penelitihan yang dilakukan oleh Abdul Rahman Malik dalam jurnal berjudul Abrogasi dalam Alquran Studi Nasikh dan Mansukh, tulisan ini menjelaskan tema nasikh dan mansukh adalah tema pokok dalam Ulumul Qur'an, kajian nasikh dan mansukh penting untuk mengetahui dinamika suatu hukum, kesimpulannya kajian nasikh dan mansukh adalah kajian yang berhubungan dengan perintah dan larangan bukan terkait dengan hal-hal akidah, akhlak dan pokok ibadah. $^{7}$

Skripsi berjudul "Studi Analisa Teori Nasikh Mansukh Ricrad Bell Dalam Buku Bellsi Introduction To The Quran" ditulis oleh Moch Khoirul Anam, dalam skripsi ini penulis menjelaskan Ricrad Bell sepakat dengan adanya nasikh sebagai pembatalan, penghapusan dan

5 Hasan Asyari Ulamai, “Konsep Nasikh Dan Mansukh Dalam Al-Quran” Didaktika Islamika 7 No 1 (Februari 2016): 63-84.

6 Labibul Wildan "Konsep Naskh Dan Mansukh Dalam Perspektif Akhmad Mustafa AlMaragi Dan Mamoud Taha” Tesis Program Pasca Sarjana Uin Sunan Ampel Surabaya 2016.

7 Abdul Rahman Malik, "Abrogasi Dalam Alquran: Studi Nasikh Dan Mansukh," Jurnal Studi Al-Qur'an 12, No. 1 (1 Januari 2016): 98-113, Https://Doi.Org/10.21009/Jsq.012.1.06. 
penggantian ayat yang sudah turun dengan ayat yang turun setelahnya, karena Alquran adalah sumber wahyu yang memiliki sifat ganda yakni Allah dan nabi Muhammad, pendapat tersebut disebabkan karena Ricrad menempatkan nabi Muhammad sebagai revisor Alquran, walaupun tetap dengan petunjuk Allah. ${ }^{8}$

Kemudian tulisan saudara M. Firdaus dengan judul "Revormulasi Nasakh Sebagai Paradigma Dinamisasi Hukum Islam” tulisan ini menawarkan paradigma nasikh yang mencoba mengelaborasikan makna nasikh secara bahasa dengan teks-teks Alquran yang menjelaskan nasikh, hasil dari analisanya penulis menemukan paradigma nasikh dapat diformulasikan menjadi tiga, yaitu nasikh eliminatif, nasikh subtitutif dan nasikh transformatif. ${ }^{9}$

Terkait Abdullah Saeed peneliti menemukan jurnal berjudul "Trend Pemikiran Islam Progresif (Telaah Atas Pemikiran Abdullah Saeed)" yang dituis oleh Anik Faridah, tuilsan ini membahas secara singkat pemikiran progresif Abdullah Saeed. Hasil dari analisisnya penulis menemukan saeed menawarkan konsep pemahaman Islam dengan usaha menafsiri ulang pemahaman agama dengan metodologi ilmu-ilmu modern sebagai solusi untuk memenuhi kebutuhan Islam saat ini. ${ }^{10}$

Tulisan saudara Annas Rolli Muchlisin dengan judul "Penafsiran Kontekstual: Studi Atas Konsep Hierarki Nilai Abdullah Saeed" dalam tulisan ini mengkaji pemikiran Saeed dalam buku Interpreting the Qur'an Towards A Contemporary Approach yang di dalamnya Saeed menaarkan metode interpretasi kontekstual dalam menafsiri Alquran. Hasil dari analisa saudara Annas, ia menemukan bahwa

8 Moch Khoirul Anam "Studi Analisa Teori Nasikh Mansukh Ricrad Bell Dalam Buku Bell's Introduction To The Quran" Skripsi Fakultas Ushuluddin Insitut Agama Islam Negeri Walisongo Semarang, 2012.

9 M. Firdaus "Reformulasi Nasikh Sebagai Paradigma Dinamisasi Hukum Islam" Istinbath 10, No 1(Juni, 2014):99-125

10 Anik Faridah "Trend Pemikiran Islam Progresif (Telaah Atas Pemikiran Abdullah Saeed)" Al-Mabsut 7, No 2 (2013): 1-12 
konsep hierarki nilai yang ditawarkan oleh Saeed adalah kelanjutan dari "general principles" yang ditawarkan oleh Fazlur Rahman. ${ }^{11}$

Kemudian tulisan M. Solahudin berjudul "Membincang Pendekatan Kontekstualis Abdullah Saeed Dalam Memahami AlQur'an” tulisan ini berusaha membahas pendekatan kontekstualis yang ditawarkan oleh Saeed beserta langkah-langkahnya, hasil dari analisisnya saudara Solahudin menemukan empat langkah dalam teori kontekstualis yang ditawarkan Saeed yaitu pertama: bertemu dengan dunia teks, kedua: melakukan analisis kritis, ketiga: menemukan makna sesuai dengan konteks turunya ayat, keempat: menemukan makna sesuai dengan kondisi dan situasi saat ini. ${ }^{12}$ Sebatas jangkauan peneliti, peneliti tidak menemukan konsep nasikh dan mansukh diteliti menurut perspektif Abdullah Saeed, sehingga peneliti menyimpulkan penelitian "Konsep Nasikh Mansukh Menurut Persektif Hermeneutika Adullah Saeed" sangat layak untuk dikaji.

\section{BIOGRAFI ABDULLAH SAEED}

Abdullah Saeed adalah keturunan dari suku Arab Oman yang lahir pada tanggal 5 September 1964 di Malsives. Dari kecil hingga menginjak remaja beliau tinggal di Meedhoo. Namun kemudian pindah ke Saudi Arabia pada tahun 1977 untuk menuntut ilmu di berbagai lembaga pendidikan formal, seperti; Insitut Bahasa Arab Dasar pada tahun 1977-1979 dilanjutkan di Insitut Bahasa Arab menengah tahun 1979-1982 terahir beliau melanjutkan di Universitas Islam Saudi Arabia Madinah dalam bahasa Arab dan Studi Islam hingga mendapat gelar BA (Bachelor's of Arts) tahun 1982-1986. ${ }^{13}$

11 Annas Rolli Muchlisin "Penafsiran Kontekstual: Studi Atas Konsep Hierarki Nilai Abdullah Saeed" Maghza 1, No. 1, (Januari-Juni 2016): 19-30

12 M. Salahudin, "Membincang Pendekatan Kontekstualis Abdullah Saeed Dalam Memahami Al-Qur'an," Qof 2, No. 1 (22 Januari 2018): 50-64.

13 M. K. Ridwan, "Metodologi Penafsiran Kontekstual; Analisis Gagasan Dan Prinsip Kunci Penafsiran Kontekstual Abdullah Saeed," Millati: Journal Of Islamic Studies And 
Saeed kemudian melanjutkan ke negeri kanguru Australia untuk menyelesaikan studi stara satu hingga studi doktoral. Beliau menerima gelar sarjana stara satu (Master of Arts Preliminary) dalam jururan studi Timur Tengah di Universitas Melboume Australia tahun 1987, gelar Master dalam jurusan Linguistik Terapan tahun 1988-1992 dan gelar doktoral dalam studi Islam tahun 1992-1994, kemudian mengabdi di universitar tersebut hingga sekarang. ${ }^{14}$

Banyak sekali karya yang dihasilkan Saeed yang menunjukkan beliau adalah seorang penulis produktif, berikut karya-karya beliau yang berkaitan dengan Alquran, Reading the Quran in the TwentyFrirst Century: A Conextualist Approach (New York: Rautledge, 2013), The Qur'an: An Introduction (New York: Routledge, 2008), ${ }^{15}$ Interpreting the Qu'an: Toward a Contemorary Approach (Routledge, 2006), Contemporary Approaches to Qur'an in Indonesia, sebagai editornya (Oxford University Press, 2005). ${ }^{16}$

Selain kajian terkait Alquran, Saeed juga menulis terkait beberapa hal seperti dalam karyannya: Islam in Australia (Sydney: Allen dan Unwin, 2003), Fredom of Religion: Apostasy and Islam (Ashgate Publishing, 2004), Muslim Australians: Their Beliefs, Practices and Instititions (Commonwealth Government, 2004), menjadi editor bersama S. Akbarzadeh dalam karya Islam and Political Legitimacy (Curson, 2003) dan Muslim Communities in Australia (University of New Sauth Waless Press, 2002). ${ }^{17}$

Humanities 1, No. 1 (15 Juni 2016): 1-22, Https://Doi.Org/10.18326/Mlt.V1i1.5.

14 Sheyla Nichlatus Sovia, "Interpretasi Kontekstual (Studi Pemikiran Hermeneutika Al-Qur'an Abdullah Saeed)," Dialogia 13, No. 1 (8 Desember 2016):39, Https://Doi. Org/10.21154/Dialogia.V13i1.282.

15 Imron Mustofa, "Kritik Metode Kontekstualisasi Penafsiran Al-Qur'ân Abdullah Saeed," Islamica: Jurnal Studi Keislaman 10, No. 2 (1 Maret 2016): 467, Https://Doi.Org/10.15642/ Islamica.2016.10.2.465-491.

16 Sovia, "Interpretasi Kontekstual (Studi Pemikiran Hermeneutika Al-Qur'an Abdullah Saeed)," 40.

17 Sovia, 40. 
Selain karya buku beliau juga menulis beberapa artikel dan makalah seperti Islamic Reform: Salafiya, Modernism and revival dalam John L. Esposito dan Emad Sahin (eds), Oxford Handbook of Islam and Politics. Oxford: Oxford Unifersity Press, Islamic Lo and International Human Righ Law: Searching for Common Ground? New York: Oxford University Prees dan masih banyak lagi. ${ }^{18}$

\section{KONSEP NASIKH MANSUKH SECARA UMUM}

Secara bahasa nasikh berarti menukil atau menyalin seperti dalam ungkapan nasakhtu al-kitab artinya saya menyalin buku dan diartikan dengan menghapus, pengertian ini merujuk pada ungkapan nasakhtu al-syamsa al-dill yang artinya matahari menghapus bayangan $^{19}$, pengertian pertama yakni menukil atau menyalin lebih tepat diterapkan pada karya ilmiah atau karya lainnya yang bahan tulisannya merupakan hasil nukilan dari teks dalam buku lain sebagai sumber rujukan. Dan keduanya baik yang dinukil atau yang menukil masih tetap bisa dipakai, tetapi definisi ini tidak tepat diterapkan untuk nasikh dalam ulumul Qur'an. Sedang pengertian yang kedua yakni menghapus, pengertian inilah yang menurut peneliti lebih tepat diterapkan untuk teori nasikh dalam ulumul Qur'an.

Manna Kholil al-Qattan dalam kitabnya Mabahis fi Ulumilquran menjelaskan secara istilah nasikh adalah penghapusan hukum syara' (hukum apapun secara mutlak) dengan hukum syara' yang lain, penghapusan tersebut mengecualikan penghapusan yang disebabkan oleh kematian atau gila. Pendapat ini dikuatkan dengan firman Allah

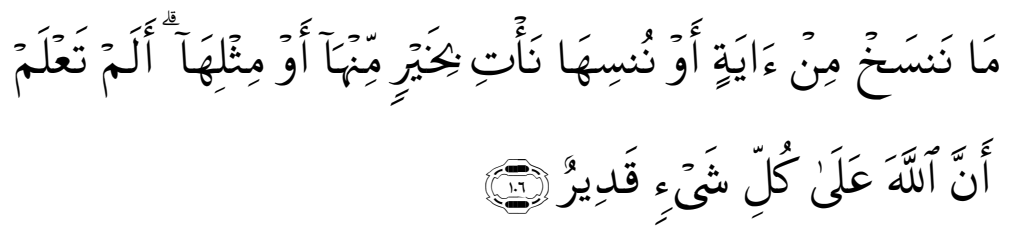

18 Mustofa, "Kritik Metode Kontekstualisasi Penafsiran Al-Qurân Abdullah Saeed," 467. 19 M. Quraish Shihab Kaidah Tafsir (Jakarta: Lentera Hati, 2013), Hal. 281 
Ayat mana saja yang Kami nasakhkan, atau Kami jadikan (manusia) lupa kepadanya, Kami datangkan yang lebih baik dari padanya atau yang sebanding dengannya. tidakkah kamu mengetahui bahwa Sesungguhnya Allah Maha Kuasa atas segala sesuatu?

Sedangkan pengertian mansukh adalah obyek atau hukum yang dihapus, beliau mencontohkan dengan mengambil permasalahan penghapusan hukum wasiat oleh hukum warisan. ${ }^{20}$

Untuk kriteria Syeh Kholil al-Qattan memberikan beberapa syarat yakni:

1. Hukum yang dihapus harus berupa hukum syara', sehingga jika hukum yang dihapus bukan merupakan hukum syara' seperti hukum yang berlaku di suatu lembaga atau komunitas tertentu maka hal tersebut tidak bisa dikatakan sebagai nasikh mansukh.

2. Dalil yang menghapus adalah hukum syar'i yang datang setelahnya. Sehingga ketika terjadi kontradiksi antara ayat tidak bisa dikatakan bahwa hukum yang datang lebih awal menghapus hukum yang datang setelahnya.

3. Hukum yang dihapus tidak dibatasi oleh waktu tertentu, sehingga penghapusan hukum bukan disebabkan karena hukum yang awal telah habis waktunya sehingga harus digantikan. $^{21}$

Pendapat ini hampir sejalan dengan ulama' ushul seperti Abdul Wahhab Khalaf dalam kitab Ilmu Ushul Fiqh yakni nasikh adalah pembatalan hukum syara' yang telah berlaku dengan hukum syara' yang datang setelahnya. Dengan beberapa kriteria yakni:

20 Manna Kholil Al-Qattan Pengantar Studi Ilmu Alquran (Jakarta:Pustaka Al-Kaustar, 2008) Hal, 286

21 Manna Kholil Al-Qattan Pengantar Studi Ilmu Alquran... Hal, 286 
1. Nasikh dan mansukh harus ditempat yang terpisah, maksudnya tidak bisa ayat nasikh dengan ayat mansukh kedua masih ada dan berada dalam satu tempat yang sama.

2. Nasikh harus lebih kuat dari mansukh atau sejajar, pendapat ini tidak bisa menerima jika ayat nasikh derajatnya dibawah hukum mansukh.

3. Mansukh tidak dibatasi oleh waktu tertentu.

4. Mansukh harus berupa hukum syara'.

5. Hukum nasikh harus datang setelah hukum mansukh. ${ }^{22}$

Dijelaskan oleh Az-Zarqani dalam kitab Manahilil Irfan bahwa pengertian nasikh secara istilah sangat banyak sekali dan beragam, namun dari semua pendapat secara umum adalah sama ${ }^{23}$ yakni pengapusan hukum syara' dengan hukum syara' yang datang setelahnya, sehingga kedua pendapat di atas sebatas analisa peneliti cukup untuk mewakili pendapat yang sepakat dengan adanya konsep nasikh mansukh baik dari ulama' mufassirin atau usulliyyin.

\section{KONSEP NASIKH MANSUKH ABDULLAH SAEED}

Nasikh secara terminologi adalah menurut Saeed adalah pencabutan suatu hukum dengan hukum yang datang setelahnya, pendapat ini beliau sandarkan dari beberapa ayat Alquran, salah satu di antaranya yaitu QS al-Baqarah: 106

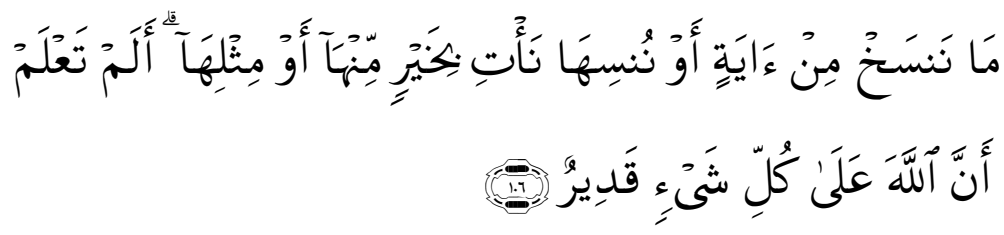

22 Subaidi "Historisitas Nasikh Mansukh Dan Problematikanya Dala Penafsiran Alquran" Hermeneutika 8, No 1 (Juni, 2014): 60

23 Wartoyo "Konsep Naskh Dalam Teori Hukum Mahmud Muhammad Thaha”... Hal. 148 
Ayat mana saja yang Kami nasakhkan, atau Kami jadikan (manusia) lupa kepadanya, Kami datangkan yang lebih baik daripadanya atau yang sebanding dengannya. tidakkah kamu mengetahui bahwa Sesungguhnya Allah Maha Kuasa atas segala sesuatu?

Pendapat ini juga disepakati oleh jumhurul Ulama’. Menurut Jumhur dalam faktanya hukum-hukum Alquran memang telah mengalami pencabutan, walaupun terkadang pencabutan diganti dengan hukum yang sangat berbeda. ${ }^{24}$ Dari sini terlihat Saeed sepakat bahkan mendukung pendapat ulama' yang sepakat dengan adanya nasikh mansukh.

Dari pengertian di atas Saeed mengklasifikasi nasikh dalam 4 hal, yakni: nasikh Alquran dengan Alquran, nasikh Alquran dengan hadist, nasikh hadis dengan Alquran, nasikh hadist dengan hadist. Menurutnya tidak ada pertentangan ulama' untuk klasifikasi bentuk nasikh seperti tersebut kecuali pada nasikh Alquran dengan hadis, namun masih ada yang memperbolehkan jika hadis yang menasikh Alquran adalah hadis metawatir seperti Abu Hanifah, Malik bin Annas dan Malik bin Hambal. ${ }^{25}$

Sampai pada pembahasan di atas Saeed masih merujuk pada jumhurul ulama' tanpa memberikan pendapatnya sendiri, namun kemudian Saeed membagi lagi pada ayat-ayat yang dinasikh menjadi tiga hal, yakni nasikh hukum sekaligus bacaan, nasikh hukum tetapi bacaannya tetap dan nasikh bacaan namun hukumnya masih tetap berlaku. ${ }^{26}$ Pendapat ini walaupun dalam bukunya Saeed tidak menyantumkan catatan kaki sebagaimana keterangan yang Saeed jelaskan terkait pengertian nasikh dan bentuk-bentuknya, namun peneliti menemukan klasifikasi tiga jenis ayat nasikh juga dijelaskan oleh Muhammad al-Kaylani dalam kitab Tahqiqat yang merupakan salah satu dari ulama' ushul ${ }^{27}$ dan dijelaskan pula oleh Khalil al-

24 Lien Iffah Naf'atu Fina Penafsiran Kontekstualis Atas Al-Qur'an... Hal. 151

25 Lien Iffah Naf'atu Fina Penafsiran Kontekstualis Atas Al-Qur'an... Hal, 152

26 Lien Iffah Naf'atu Fina Penafsiran Kontekstualis Atas Al-Qur'an... Hal, 155

27 Ahmad Hasanuddin Berutu “Teori Nasikh Mansukh Imam Syafi'i Dan Relevansinya 
Qatthan dalam Mabahis fi Ulumilqur'an ${ }^{28}$ artinya, dengan hal tersebut menunjukan Saeed masih sependapat dengan pendapat jumhurul ulama'.

Konsep nasikh menurut Saeed sendiri adalah sebuah gagasan yang dapat menjadi sandaran perkembangnya hukum dalam Alquran, maksudnya dengan adanya nasikh Alquran sejak masa Rasulullah Allah telah menunjukan adanya perubahan hukum yang sebelumnya telah ditetapkan sesuai dengan kondisi dan situasi yang berbeda. ${ }^{29}$

Konsep yang dibangun Saeed inilah yang menjadi pembeda antara pendapatnya dengan pendapat jumhurul ulama'. Jumurul ulama' sepakat dengan adanya nasik mansukh tetapi mereka memiliki kriteria bahwa ayat atau hukum bisa dikatakan di nasikh dengan hukum yang lain harus dengan adanya nas-nas dari Alquran atau hadis yang mengindikasikan adanya nasikh, seperti terdapat kontradiksi antara dua hukum namun harus diketahui mana yang lebih dahulu ditetapkan, ada penjelasan tegas dari nabi shahabat bahwa hukum tersebut di nasikh dan terakhir harus mendapat kesepakatan atau ijma' yang mengatakan bahwa hukum tersebut di nasikh ${ }^{30}$ selain dari itu hukum tidak bisa bisa dikatakan sebagai telah menasikh atau dimansukh.

Saeed justru malah menjadikan nasikh mansukh sebagai pijakan awal untuk mengkontekstualisasikan hukum Alquran dengan melihat kondisi dan situasi yang terjadi. Walaupun Saeed tidak mengatakan bahwa hasil dari kontekstualisai hukum berarti menjadi nasikh, namun perubahan hukum yang terjadi lewat adanya nasikh mansukh pada saat itu menurutnya bisa menjadi alasan perubahan hukum untuk konteks sekarang dengan melihat kondisi dan situasi saat ini dan alasan itu tidak digunakan oleh jumhurul ulama. ${ }^{31}$

Dalam Pemabeharuan Fiqih Di Indonesia" Skripsi Fakultas Syariah, Progarm Studi AlAhwal Al-Syakhshiyah, Universitas Islam Negeri Malang, 2008, Hal 49-50.

28 Manna Kholil Al-Qattan Pengantar Studi Ilmu Alquran... Hal, 293-295.

29 Lien Iffah Naf'atu Fina Penafsiran Kontekstualis Atas Al-Quran... Hal, 160-161

30 Manna Kholil Al-Qattan Pengantar Studi Ilmu Alquran... Hal, 288

31 Lien Iffah Naf'atu Fina Penafsiran Kontekstualis Atas Al-Qur'an... Hal 149 
Bagi Saeed kelompok tekstualis atau semi tekstualis yang menyakini bahwa apapun hukum yang tertulis dalam Alquran atau sunnah harus selalu diamalkan tanpa memandang situasi dan kondisi bahkan manusia harus selalu dipaksa untuk selalu menyesuaikan dengan kondisi sesuai dengan hukum yang tertulis dalam Alquran dan sunnah, pendapat tersebut menurut Saeed justru mengabaikan gagasan penting dari adanya konsep nasikh mansukh ${ }^{32}$

Alasan Saeed untuk menguatkan pendapatnya adalah dengan melihat bahwa Alquran diturunkan selama 22 tahun dan hukum dalam Alquran telah mengalami beberapa kali perubahan sebagai solusi untuk memenuhi kebutuhan masyarakat pada saat itu. ${ }^{33}$ Sehingga untuk saat ini walaupun tidak ada dalil yang menunjukkan bahwa hukum telah di nasikh oleh hukum yang lain tetapi dengan tujuan untuk memenuhi kebutuhan masyarakat sekarang yang tentu sangat berbeda jauh dengan keadaan pada masa Rasulullah maka hukum bisa saja berubah.

Saeed mencontohkan dengan mengambil kasus khamr. Pertama ayat Alquran hanya mengatakan bahwa meminum khamr hukumnya dosa besar. Kedua ayat Alquran melarang orang mukmin shalat setelah meminum khamr. Ketiga secara jelas ayat Alquran mengatakan bahwa orang mukmin wajib meninggalkan khamr secara total. ${ }^{34}$

Kemudian Saeed juga berargumen dengan perubahan hukum yang terjadi di Madinah yakni dalam kasus perang, saat orang mukmin masih di Makkah meraka hanyalah sekelompok minoritas yang belum mampu melawan kaum kafir Quraisy keadaan ini sangat jauh berbeda ketika orang-orang mukmin hijrah di Madinah. Dengan perubahan kondisi umat Islam yang semula lemah menjadi sangat kuat, petunjuk Alquran dalam banyak hal pun menjadi berubah. ${ }^{35}$

32 Lien Iffah Naf'atu Fina Penafsiran Kontekstualis Atas Al-Qur'an... Hal, 161

33 Lien Iffah Naf'atu Fina Penafsiran Kontekstualis Atas Al-Qur'an... Hal, 149

34 Lien Iffah Naf'atu Fina Penafsiran Kontekstualis Atas Al-Qur'an... Hal, 162

35 Lien Iffah Naf'atu Fina Penafsiran Kontekstualis Atas Al-Qur'an... Hal, 164-165 
Saeed mengkritik ulama' seperti Zarkasyi dan imam Suyuti yang tidak mau menggunakan konsep nasikh sebagai alasan untuk menafsiri ulang ayat-ayat Alquran yang seraca logis menurut Saeed sudah tidak relevan dengan memenuhi kebutuhan masyarakat. Menurutnya seharusnya Alquran dapat memberikan dasar-dasar yang kuat dan logis bagi masyarakat dan jika itu sudah tidak bisa maka perlu adanya penafsiran ulang. ${ }^{36}$

Dalam pandangan Saeed sebagai salah satu dari mufasir kontekstualis adanya nasikh sebagai perubahan hukum ketika kondisi dan situasi berubah menunjukan bahwa Allah telah memberi petunjuk pada umat muslim sejak saat itu agar mau manggunakan nasikh sebagai alat pijakan penting untuk merubah hukum sesuai dengan kondisi dan situasi yang selalu berubah. ${ }^{37}$ Menurut peneliti konsep nasikh sengaja dijadikan alasan kuat Saeed untuk mengkontekstualisasikan ayat dengan keadaan sekarang sebagai solusi untuk memenuhi kebutuhan karena ayat Alquran sudah tidak turun sehingga perubahan hukum adalah dengan cara menafsiri ulang.

Selain alasan di atas menurut Saeed nasikh juga dapat menjadi solusi untuk memudahkan umat yang sering sekali mengalami kesulitan dalam membedakan antara hukum yang terdapat dalam teks dengan tujuan moral yang diinginkan oleh teks sehingga hukum yang terdapat dalam teks hanyalah sebagai salah satu alternatif untuk memperoleh tujuan moral. ${ }^{38}$ Karena dalam beberapa kasus nasikh, menurut Saeed sebenarnya bukan tujuan dari hukum yang di nasikh, artinya walaupun suatu ayat telah dinasikh namun antara ayat yang nasikh dan mansukh tetap dalam tujuan yang sama, contoh seperti dalam kasus zina. Pertama ayat Alquran menetapkan hukum kurungan bagi pelaku zina sampai ia meninggal, tujuannya adalah untuk mencegah

36 Lien Iffah Naf'atu Fina Penafsiran Kontekstualis Atas Al-Qur'an... Hal, 165

37 Lien Iffah Naf'atu Fina Penafsiran Kontekstualis Atas Al-Qur'an... Hal, 163

38 Lien Iffah Naf'atu Fina Penafsiran Kontekstualis Atas Al-Qur'an... Hal, 167 
agar pelaku zina tidak mengulangi perbuatnnya. Kedua hukum bagi pelaku zina diganti dengan hukuman cambuk sampai ia meninggal. Antara hukum pertama dan kedua tetap dalam tujuan yang sama yakni mencegah perbuatan yang tidak bermoral dan bertentangan dengan Islam. Artinya hukum kurungan atau cambuk bukanlah tujuan dari Alquran, kedua hukum tersebut hanyalah oprasional dari tujuan Alquran mencegah perbuatan yang dilarang Islam. ${ }^{39}$

Dari penjelasan tersebut Saeed mengaskan bahwa hukum yang terdapat dalam redaksi ayat harus dipahami terlebih dahulu apakah itu merupakan tujuan yang diinginkan oleh Alquran atau hanya sekedar sebagai oprasional dari tujuan Alquran, hal ini berguna untuk menemukan tujuan sesunguhnya yang diinginkan oleh Alquran, setelah diketahui apa yang menjadi tujuan dari Alquran langkah selanjutnya adalah melihat metode yang digunakan oleh Alquran untuk memperoleh tujuan, dan kondisi dan situasi harus selalu menjadi pertimbangan. ${ }^{40}$

Inti dari penjelasan tersebut yang diinginkan oleh Saeed adalah jika hukum yang tertulis dalam ayat diketahui hanya sebagai oprasional untuk memperoleh tujuan, ketika hukum tersebut sudah tidak lagi relevan dengan tujuan melihat dari kondisi dan situasi yang berbeda maka perlu adanya penafsiran ulang demi untuk mendapatkan tujuan yang sebenarnya diinginkan oleh Alquran. Dan hal tersebut telah ditunjukan oleh adanya konsep nasikh mansukh.

Yang peneliti tangkap dari penjelasan di atas nasikh menurut Saeed adalah pembatalan hukum dan yang diinginkan Saeed adalah menekankan bahwa konsep nasikh mansukh memberi gagasan yang sangat logis bahwa hukum yang berlaku bisa saja mengalami pembatalan demi untuk memenuhi kebutuhan umat karena kondisi dan situasi yang berbeda, jika dulu Alquran masih turun maka solusi dari Allah untuk memenuhi kebutuhan umat adalah dengan

39 Lien Iffah Naf'atu Fina Penafsiran Kontekstualis Atas Al-Qur'an... Hal, 168

40 Lien Iffah Naf'atu Fina Penafsiran Kontekstualis Atas Al-Qur'an... Hal, 168 
membatalkan hukum yang sudah berlaku dengan menurunkan hukum baru atau nasikh mansukh, namun karena sekarang ayat Alquran sudah lagi turun maka untuk memenuhi kebutuhan umat adalah dengan cara menafsiri ulang Alquran.

Apakah kemudian hasil penafsiran ulang dari hukum yang sudah berlaku disebut sebagai nasikh atau hukum yang membatalkan dan hukum yang diganti atau dibatalkan disebut sebagai mansukh, Saeed tidak menjelaskannya. Kemudian apakah nanti hukum yang telah diganti atau dibatalkan baik karena proses penafsiran ulang atau Allah mengganti dengan hukum baru jika nanti kondisi dan situasi memungkinkan bisa berlaku kembali Saeed juga tidak menjelaskan.

Kedua pertanyaan tersebut menurut peneliti menjadi kekurangan Saeed karena dia tetap menyakini bahwa nasikh adalah pembatalan hukum tetapi kemudian gagasan dari adanya nasikh mansukh dijadikan sebuah pijakan untuk mengkontekstualisasikan Alquran dengan masa sekarang dengan cara menafsiri ulang sesuai dengan kondisi dan situasi.

Sedikit ada perbedaan dan persamaan dengan konsep nasikh mansukh yang ditawarkan oleh Abdullah Ahmad an-Na'im yang menyakini adanya nasikh mansukh tetapi tidak dengan pengertian nasikh sebagai pembatalan hukum melainkan penundaan artinya menunda pelaksanaan dan penerapan ayat, sehingga ayat yang telah dinasikh ketika nanti datang kondisi atau situasi yang mengharuskan ayat tersebut digunakan maka akan diberlakukan kembali. Sedangkan ayat yang sebelumnya menasikh menjadi ditangguhkan sampai kondisi dan situasi memang membutuhkannya. Jadi nasikh bukanlah pembatalan secara mutlak melainkan penundaan sampai pada waktunya harus digunakan kembali. Hal penting yang ingin ditekankan oleh an-Na'im adalah Alquran diturunkan sesuai dengan kebutuhan umat. Sehingga nabi Muhammad sebagai penerima wahyu bertugas 
untuk menyampaikan dan mengamalkan ayat Alquran yang memang sesuai dengan kebutuhan umat. ${ }^{41}$

Hampir sama dengan an-Na'im, Narsh Hamid Abu Zayd juga mengartikan nasikh bukan sebagai pembatalan tetapi penggantian maksudnya nasikh bukanlah sebuah penghapusan hukum melainkan penggantian hukum tetapi kedua hukum tersebut baik nasikh atau mansukh tetap masih berlaku sesuai dengan kondisi dan situasi. Konsep nasikh menurut Abu Zayd adalah bertujuan untuk memberikan hukum secara bertahap sesuai dengan kebutuhan umat karena menurutnya Alquran bersifat operatif dan fungsional sehingga terjadinya nasikh adalah sebagai bentuk penangguhan hukum sementara yang disesuaikan dengan situasi dan kondisi, menurutnya jika nasikh diartikan dengan pembatalan secara total, maka hal tersebut sangat bertentangan dengan tujuan memudahkan, penahapan dan kelonggaran dalam hukum. ${ }^{42}$

Menurut peneliti, jika Saeed bertujuan menjadikan nasikh mansukh sebagai sebuah gagasan untuk menafsiri ulang Alquran agar sesuai dengan kondisi dan situasi kebutuhan umat maka seharusnya nasikh tidak diartikan sebagai bentuk pembatalan, melainkan penundaan seperti yang dilakukan An-Na'im atau penggantian seperti yang dijelaskan oleh Abu Zayd dengan catatan baik hukum yang menasikh atau yang dimansukh tetap bisa diaplikasikan sesuai dengan kondisi dan situasi kebutuhan umat. Atau bisa juga nasikh diartikan sebagai pembatalan tetapi harus dijelaskan tidak bersifat mutlak artinya ketika nanti kondisi dan situasi umat membutuhkan

41 Zainul Mun’im “Teori Nasikh Mansukh Alquran Sebagai Pembeharuan Hukum Islam (Studi Pemikiran Abdullah Ahmed An-Na’i Dan Muhammmad Syahrur)" Skripsi Fakultas Syariah Dan Hukum, Universitas Islam Negeri Sunan Kalijaga Yogyakarta 2013, Hal 53-62

42 Muhammad Fajri "Konsep Nasikh Mansukh Menurut Nasr Hamid Abu Zayd” Skripsi Jurusan Ilmu Alquran Dan Tafsir Fakultas Ushuluddin Dan Pemikiran Islam, Universitas Islam Negeri Sunan Kalijaga Yogyakarta 2017, Hal, 63 
ayat yang telah dinasikh tetap bisa ditafsiri ulang sesuai dengan kebutuhan umat.

\section{KESIMPULAN}

Hasil analisa dari pemaparan di atas peneliti menemukan konsep nasikh menurut Saeed adalah pencabutan hukum dengan hukum yang datang setelanya, alasan Saeed setuju dengan adanya nasikh mansukh dalam Alquran adalah sebagai bentuk kemudahan yang Allah berikan kepada umat sesuai dengan kondisi dan situasi kebutuhan umat, kemudian untuk relevansi nasikh menurut Saeed dalam penafsiran adalah gagasan pencabutan hukum lewat nasikh dapat menjadi pijakan untuk menafsiri ulang Alquran yang sudah tidak relevan agar bisa memenuhi kebutuhan umat yang sesuai dengan kondisi dan situasi.

Pendapat Saeed walaupun telah mengalami perkembangan namun masih ada persamaan dengan jumhurul ulama' baik mufasir atau ushulliyin. Namun semangat Saeed untuk menjadikan nasikh sebagai pijakan menafsiri ulang Alquran agar sesuai dengan kondisi dan situasi kebutuhan umat itulah yang membedakan pendapat Saeed dengan jumhurul ulama’ yang menurut Saeed tidak menyadari bahkan cenderung mengabaikan.

Untuk semangat Saeed menjadikan nasikh sebagai pijakan untuk menafsiri ulang Alquran agar sesuai dengan kondisi dan situasi menurut peneliti sedikit ada persamaan dengan pendapat an-Na'im dan Abu Zayd yang memiliki pendapat nasikh mansukh adalah bentuk dari penundaan dan penggantian hukum agar sesuai dengan kondisi dan situasi, perbedaannya terletak pada Saeed tidak menjelaskan apakah dengan menafsiri ulang ayat-ayat yang diyakini telah mengalami pembatalan atau dinasikh bisa diaplikasikan kembali ketika nanti kondisi da situasi membutuhkan, sedangkan an-Na'im dan Abu Zayd dari awal membatasi bahwa ayat yang menasikh dan yang dinasikh tetap bisa diberlakukan kembali sesuai dengan situasi dan kondisi. 


\section{DAFTAR PUSTAKA}

Al-Qattan, Manna Kholil Pengantar Studi Ilmu Alquran Jakarta:Pustaka Al-Kaustar, 2008

Anam, Moch Khoirul "Studi Analisa Teori Nasikh Mansukh Ricrad Bell Dalam Buku Bell's Introduction To The Quran” Skripsi Fakultas Ushuluddin Insitut Agama Islam Negeri Walisongo Semarang, 2012.

Bakar, Abu. "Kontraversi Nasikh Dan Mansukh Dalam Al-Qur'an." Madania: Jurnal Ilmu-Ilmu Keislaman 6, No. 1 (1 Maret 2018): 47-64.

Fajri, Muhammad "Konsep Nasikh Mansukh Menurut Nasr Hamid Abu Zayd" Skripsi Jurusan Ilmu Alquran Dan Tafsir Fakultas Ushuluddin Dan Pemikiran Islam, Universitas Islam Negeri Sunan Kalijaga Yogyakarta 2017

Faridah, Anik “Trend Pemikiran Islam Progresif (Telaah Atas Pemikiran Abdullah Saeed)" Al-Mabsut 7, No 2 (2013): 1-12

Firdaus, M. "Reformulasi Nasikh Sebagai Paradigma Dinamisasi Hukum Islam” Istinbath 10, No 1(Juni, 2014): 99-125

Hasanuddin, Ahmad Berutu “Teori Nasikh Mansukh Imam Syafi'i Dan Relevansinya Dalam Pemabeharuan Fiqih Di Indonesia” Skripsi Fakultas Syariah, Progarm Studi Al-Ahwal Al-Syakhshiyah, Universitas Islam Negeri Malang, 2008

Iffah, Lien Naf'atu Fina Penafsiran Kontekstualis Atas Al-Qur'an, Terjemahan Dari Buku Interpretasi The Qur'an: Towards A Contemprary Approach, Yogyakarta: Lembaga Ladang Kata, 2016 Malik, Abdul Rahman. "Abrogasi Dalam Alquran: Studi Nasikh Dan Mansukh.” Jurnal Studi Al-Qur'an 12, No. 1 (1 Januari 2016): 98-113. Https://Doi.Org/10.21009/Jsq.012.1.06. 
Muchlisin, Annas Rolli "Penafsiran Kontekstual: Studi Atas Konsep Hierarki Nilai Abdullah Saeed” Maghza 1, No. 1, (Januari-Juni 2016): 19-30

Mun'im, Zainul “Teori Nasikh Mansukh Alquran Sebagai Pembeharuan Hukum Islam (Studi Pemikiran Abdullah Ahmed An-Na’i Dan Muhammmad Syahrur)" Skripsi Fakultas Syariah Dan Hukum, Universitas Islam Negeri Sunan Kalijaga Yogyakarta 2013

Mustofa, Imron. "Kritik Metode Kontekstualisasi Penafsiran AlQurân Abdullah Saeed." Islamica: Jurnal Studi Keislaman 10, No. 2 (1 Maret 2016): 465-91. Https://Doi.Org/10.15642/ Islamica.2016.10.2.465-491.

Reflita, Reflita. "Redefinisi Makna Nasakh Internal Ayat Al-Qur'an." Substantia 19, No. 1 (3 Februari 2018): 23-36.

Ridwan, M. K. "Metodologi Penafsiran Kontekstual; Analisis Gagasan Dan Prinsip Kunci Penafsiran Kontekstual Abdullah Saeed." Millati: Journal Of Islamic Studies And Humanities 1, No. 1 (15 Juni 2016): 1-22. Https://Doi.Org/10.18326/Mlt.V1i1.1-22.

Shihab, M. Quraish Kaidah Tafsir Jakarta: Lentera Hati, 2013

Sovia, Sheyla Nichlatus. "Interpretasi Kontekstual (Studi Pemikiran Hermeneutika Al-Qur'an Abdullah Saeed).” Dialogia 13, No. 1 (8 Desember 2016): 51-64. Https://Doi.Org/10.21154/Dialogia. V13i1.282.

Ulamai, Hasan Asyari. “Konsep Nasikh Dan Mansukh Dalam AlQuran” 7 (2016): 22.

Wartoyo "Konsep Naskh Dalam Teori Hukum Mahmud Muhammad Thaha" Mahkama 1, No 2 (Desember 